\title{
The Trade Potential of the Arab Gulf Cooperation Countries (GCC): A Gravity Model Approach
}

\author{
Dr. Houcine Boughanmi \\ Sultan Qaboos University
}

\begin{abstract}
The GCC region has recently witnessed the creation of a customs union between the countries of the region as well as the signature of many free trade areas with countries/blocs outside the region (i.e. US and EU). The purpose of this paper is to investigate the potential of trade of the GCC countries within the context of the old and the emerging preference trade arrangements in the region of Middle East and North African Countries (MENA). A gravity trade model was estimated based on pooled time series-cross-sectional data of bilateral trade of the MENA countries with their major trading partners. The results indicate that in spite of the fact that the share of GCC intra-trade is too small in absolute terms, it is actually higher than expected on the basis of underlying trade determinants. However the level of the GCC intra-trade has not changed significantly over the years and had probably reached its full potential during the first decade of the GCC creation. Trade with the Mashreq countries are more than expected, while it is less than expected with the Maghreb countries despite the implementation of the GAFTA a decade ago. The GCC trade with the European Union and the US was found to be quite intensive although no formal trade arrangement existed between the GCC and both blocs for the time-period used in the analysis. The results suggest that the newly signed trade arrangements are promising in enhancing new opportunities of trade in the GCC region.
\end{abstract}

\footnotetext{
*Corresponding address: Dr. Houcine Boughanmi, Associate Professor, Sultan Qaboos University College of Agricultural and Marine Sciences, Department of Agricultural Economics and Rural Studies, PO Box:34 Al Khod 123, Sultanate of Oman, Tel: +968 24141243, Fax:+968 24413418, Email: boughanh@squ.edu.om
} 


\section{- JEL classification: F15}

- Keywords: Gulf Cooperation Council (GCC), Trade potential, Gravity model, Free trade areas, Trade creatior, Trade diversion

\section{Introduction}

The countries of the Gulf Cooperation Council (GCC) have recently launched a customs union (GCC-CU) with the objectives of enhancing regional intra-trade and advancing the process of their economic integration with the rest of the world ${ }^{1}$. At the same time most GCC countries have separately signed Free Trade Areas agreements (FTA's) with the United States, and have been for long collectively engaged in negotiation with the European Union to create a GCC-EU Free Trade Area. In addition, all GCC countries are now members of the Greater Arab Free Trade Area (GAFTA) and all are members of the World Trade Organization (WTO).

This proliferation of FTA's and other integration schemes in the region is part of a recent global phenomenon. Worldwide, there has been a surge in the number of regional trade arrangements created despite the increasing role of WTO to strengthen the multilateral trading system. More than half of the existing regional trade arrangements worldwide were established after the creation of WTO in 1995 (WTO, 2005). This has renewed interest in studying the trade and non trade effects of Regional Trade Arrangements (RTA's) and their merits (or non merits) over the multilateral trading system sponsored by WTO.

The purpose of this paper is to use a gravity model to investigate the effects of the GCC, as a preferential trade arrangement, on total intra-trade and determine the trade potential of GCC with countries or groups of countries with which a preferential trade arrangement is signed or still in negotiation. A pooled time series -cross-sectional regression method is used to estimate the model based on 7500 bilateral trade observations, ranging from 1990 to 2004, and covering bilateral trade of the whole Middle East and North African countries (19 countries) with 69 trading partners (see list of countries in the appendix). The Middle East and North African region (MENA) is chosen as it represents a reference group for the GCC countries with which they have intensive trade relations in addition to their historical and cultural links.

The GCC as a Free Trade Area was created in 1983 and includes 6 members: Saudi Arabia, United Arab Emirates, Oman, Kuwait, Qatar and Bahrain. 
The gravity model has been applied to a wide variety of countries, regions and levels of commodity aggregation. In the MENA region, Al-Atrash and Yousef (2000) for example used a gravity model to address the question whether intraArab is too little. He estimated that intra-Arab trade and Arab trade with the world are lower than would be predicted by the gravity model suggesting greater scope for regional integration and multilateral integration particularly with the European Union. Within the Arab region, their results indicate that Intra-GCC and intraMaghreb trade are relatively low while that of the Mashreq countries are higher than expected ${ }^{2}$. The study is however limited to one period (average of 1995-1997) and therefore does not capture the pattern of trade over time. Nugent (2002) used a gravity model to examine the potential of intra-regional and extra-regional trade of MENA countries and to determine the extent to which intra-trade has varied across MENA sub-regions. Based on a world-wide data set covering periods from 1970 until 1997, Nugent's study showed strong evidence that sub-regional trade arrangements such as the Arab Common Market (ACM) and the Arab Maghreb Union (AMU) failed to increase trade while that evidence is weak for the GCC countries. More recently, Bolbol and Fatheldin (2005) used a gravity approach for the 1997-2003 period to analyze the determinants of intra-Arab exports and Foreign Direct Investment (FDI). Their findings indicate that intra-Arab exports are below normal and that deficiency mainly arises from the lack of enough exports between the GCC-Maghreb and Maghreb-Mashreq countries.

\section{The Structure and Direction of the GCC Trade}

The GCC countries are heavily dependent on trade with an export to GDP ratio varying from $74 \%$ in Bahrain to $40 \%$ in Saudi Arabia. The region as a whole exports annually the equivalent of $\$ 155$ billions, out of which $83 \%$ is oil (Table 1). Saudi Arabia is the most important trader, accounting for $47 \%$ of total region's exports and $37 \%$ of the region's imports, followed by UAE with a share of $22 \%$

\footnotetext{
${ }^{2}$ Maghreb Union countries are: Tunisia, Algeria, Morocco, Libya and Mauritania. Mashreq countries are: Egypt, Syria, Lebanon, Jordan, and Iraq.

${ }^{3}$ Much of the export figures for some countries include re-exports. For example a country such as UAE is major transshipment hub for the region where a significant proportion of trade destined to other GCC countries region flows thorough its ports. This trade is registered as re-exports if the product concerned has not been transformed sufficiently enough for its origin to change. According to national statistics, only $21 \%$ of UAE exports to GCC countries is of national origin.
} 
Table 1. Commodity GCC Trade, 2004(\$Millions)

\begin{tabular}{lcccccccc}
\hline & UAE & OM & BA & KU & KSA & QA & GCC & $\%$ \\
\hline Commodity Exports & 33669 & 11365 & 6632 & 16164 & 73403 & 13383 & 154615 & 100 \\
Food \& live animals & 606 & 300 & 43 & 44 & 393 & 15 & 1401 & 0.9 \\
Beverages and tobacco & 536 & 229 & 20 & 10 & 20 & 1 & 815 & 0.5 \\
Crude materials & 189 & 51 & 260 & 45 & 175 & 17 & 737 & 0.5 \\
Mineral fuels & 22152 & 9050 & 4681 & 14930 & 65208 & 12180 & 128201 & 82.9 \\
Chemicals & 600 & 123 & 198 & 803 & 5203 & 620 & 7546 & 4.9 \\
Manufactured goods & 3061 & 343 & 1028 & 118 & 1163 & 291 & 6004 & 3.9 \\
Machinery\& transport eq. & 4346 & 934 & 156 & 134 & 955 & 149 & 6674 & 4.3 \\
Others & 2180 & 335 & 245 & 81 & 284 & 110 & 3236 & 2.1 \\
Export share (\%) & 22 & 7 & 4 & 10 & 47 & 9 & 100 & \\
Commodity Imports & 30544 & 6572 & 4425 & 7869 & 31223 & 4897 & 85531 & 100 \\
Food \& live animals & 2681 & 749 & 442 & 1103 & 4226 & 413 & 9615 & 11.2 \\
Beverages and tobacco & 224 & 306 & 442 & 64 & 334 & 45 & 1417 & 1.7 \\
Crude materials & 399 & 292 & 442 & 164 & 630 & 151 & 2079 & 2.4 \\
Mineral fuels & 218 & 216 & 442 & 38 & 67 & 28 & 1010 & 1.2 \\
Chemicals & 2177 & 459 & 442 & 598 & 3070 & 312 & 7059 & 8.3 \\
Manufactured goods & 6091 & 1015 & 442 & 1363 & 5192 & 1041 & 15144 & 17.7 \\
Machinery\& transport equip. & 11391 & 2827 & 442 & 2888 & 13111 & 2322 & 32982 & 38.6 \\
Others & 7362 & 708 & 1326 & 1649 & 4594 & 585 & 16225 & 19.0 \\
Import share (\%) & 36 & 8 & 5 & 9 & 37 & 6 & 100 & \\
\hline Source Compin
\end{tabular}

Source: Compiled from COMTRADE-UN data base

and $36 \%$ respectively ${ }^{3}$. Most imports comprise machinery and equipment (39\%), manufacturing (17\%), and food (11\%).

As many GCC members are major oil exporters, most trade is conducted with non-GCC countries, particularly Japan, EU, and USA. During the period 19932004 , only $4.12 \%$ of GCC exports went to GCC markets, while $9.74 \%$ of total GCC imports originate from GCC countries (Table 2). The small observed volume of GCC intra-trade is arguably attributed to the similarity of the economic structure of the GCC member countries as well as their lack of industrial diversification (Havrylyshyn and Kusnel,1997). However, if oil is excluded from trade, the GCC intra-exports become a significant proportion of total GCC exports $(26.7 \%)$ comparable to that of successful trade arrangements like, MERCOSUR and ASEAN. This suggests that GCC intra-trade is quite intensive and the GCC economies are more trade integrated than what aggregate data (inclusive of oil) may indicate.

Table 2 also shows the trade direction of the GCC countries during the 1993- 
Table 2. GCC trade structure by source and destination (\%)

\begin{tabular}{ccccccc}
\hline Period & GCC & Arab countries & USA & EU & Asia & Others \\
\hline $93-04$ & 4.12 & 1.46 & 9.38 & 8.74 & 20.73 & 55.56 \\
$93-96$ & 4.32 & 1.38 & 11.66 & 12.30 & 14.51 & 55.84 \\
$97-00$ & 4.12 & 1.43 & 6.22 & 5.71 & 23.83 & 58.69 \\
$01-04$ & 3.91 & 1.58 & 10.26 & 8.22 & 23.86 & 52.16 \\
& & \multicolumn{5}{c}{ Total exports } \\
$93-04$ & 26.62 & 8.09 & 6.21 & 7.32 & 18.16 & 33.60 \\
$93-96$ & 30.65 & 8.26 & 6.12 & 8.10 & 27.17 & 19.69 \\
$97-00$ & 27.69 & 9.35 & 7.25 & 8.17 & 15.00 & 32.54 \\
$01-04$ & 21.52 & 6.68 & 5.24 & 5.69 & 12.31 & 48.57 \\
& & \multicolumn{5}{c}{ Total imports } \\
$93-04$ & 9.74 & 2.57 & 14.64 & 31.11 & 25.75 & 16.19 \\
$93-96$ & 8.76 & 2.64 & 17.54 & 32.30 & 23.04 & 15.72 \\
$97-00$ & 10.83 & 2.35 & 13.87 & 30.94 & 27.48 & 14.52 \\
$01-04$ & 9.61 & 2.72 & 12.51 & 30.09 & 26.73 & 18.34 \\
& & & Non-oil imports & & & \\
$93-04$ & 8.73 & 2.63 & 14.92 & 31.79 & 28.75 & 13.18 \\
$93-96$ & 7.17 & 2.70 & 17.79 & 32.85 & 28.00 & 11.49 \\
$97-00$ & 9.90 & 2.38 & 13.98 & 31.28 & 29.56 & 12.92 \\
$01-04$ & 9.12 & 2.83 & 12.98 & 31.25 & 28.70 & 15.13 \\
\hline
\end{tabular}

Source: Compiled from COMTRADE

2004 period. Asia, USA, and EU make up $21 \%, 9.4 \%$ and $8.8 \%$ of total GCC exports, while Arab countries (including GCC) make up only $6 \%$ of the regional exports. If oil is excluded, Arab countries (including GCC) draw $35 \%$ of non oil GCC exports, while the rest is directed to Asia (18\%), EU (7\%), and USA (6\%). The structure of the GCC trade is quite similar in terms of total imports and non oil imports.

In order to check for a pattern of change of the GCC trade structure over time, the 1993-2004 period is divided into three four-year sub-periods. As indicated in Table 2 there seems to be a small declining trend for the GCC intra-exports, which is much more apparent for non-oil exports (from $26.6 \%$ in $1993-1996$ to $21.5 \%$ in 2001-2004). The shortfall in intra-trade total export is compensated by an increase in export share to all GCC major partners, while the fall in non oil intra-exports is accompanied also by a fall in export shares to all major partners, and an increase in "others countries" share. The explanation of these structural changes in GCC trade requires a formal model in order to explicitly account for the various factors that 
affect bilateral trade, including the effects of the formation of trade arrangements in the region as well as the global trade openness of the GCC countries. The gravity model is the most widely used framework to address the issues raised above, given its flexibility and its empirical performance in a wider regional context.

\section{Specification of the Gravity Model}

The gravity model in its basic form postulates that the volume of bilateral trade between two countries is directly related to their incomes (GDP's) and inversely related to the distance between them ${ }^{4}$. The model used in the literature has been augmented and customized to various purposes to include other variables that capture common cultural and historical values (i.e whether a pair of countries share the same language), geography (i.e whether a pair of countries share a border) and preference trade policies.

The exact double-log specification of the model used in this analysis is: $\ln X_{i j t}=\beta_{0}+\beta_{l} \ln \left(Y_{i t}\right)+\beta_{2} \operatorname{Ln}\left(Y_{j t}\right)+\beta_{3} \ln \left(\right.$ Pop $\left._{i t}\right)+\beta_{4} \operatorname{Ln}\left(P_{o p} p_{j t}\right)+\beta_{5} \operatorname{Ln}\left(D_{i j}\right)+$ $\beta_{6}\left(\operatorname{Bord}_{i j}\right)+\beta_{7} D G C C_{i j t}+\beta_{8} D M U_{i j t}+\beta_{9} D M A S_{i j t}+\beta_{10} D G C C O_{i j t}+B_{11} D G C M U_{i j t}+$ $B_{12} D G C M A S_{i j t}+B_{13} D G C E U_{i j t}+\beta_{14} D G C U S_{i j t}+u_{i j t}$

Where:

$\mathrm{X}_{\mathrm{ijt}}$ denotes the value of trade (exports or imports) between countries $i$ and $j$ at time $t$.

$\mathrm{Y}_{\mathrm{it}}$ is nominal GDP of country $i$.

$\mathrm{Y}_{\mathrm{jt}}$ is nominal GDP of country $j$.

Pop $_{\text {it }}$ is population of country $i$.

Pop $_{\mathrm{jt}}$ is population of country $j$.

$\mathrm{D}_{\mathrm{ij}}$ is distance between $i$ and $j$.

Bord $_{\mathrm{ij}}$ is a dummy variable if $i$ and $j$ share a border.

DGCC $_{\mathrm{ij}}$ is a dummy variable, which takes the value of 1 if $i$ and $j$ are both GCC countries.

$\mathrm{DMU}_{\mathrm{ij}}$ is a dummy variable, which takes the value of one if $i$ and $j$ belong to the Maghreb Union (MU).

DMAS $_{\mathrm{ij}}$ is a dummy variable, which takes the value of 1 if $i$ and $j$ are both Mashreq countries.

\footnotetext{
${ }^{4}$ The gravity model used in international trade draws its name from the Newton's law that relates the gravity attraction between two objects to their masses and the distance between them.
} 
DGCCO $_{\mathrm{ijt}}$ is a dummy variable, which takes the value of 1 if $i$ is a GCC country but $j$ is not.

DGCMU $_{\mathrm{ijt}}$ is a dummy variable, which takes the value of 1 if $i$ is a GCC country and $j$ is a Maghreb Union country.

DGCMA $_{\mathrm{ijt}}$ is a dummy variable, which takes the value of 1 if $i$ is a GCC country and $j$ is a Mashreq country.

DGCEU $_{\mathrm{ijt}}$ is a dummy variable, which takes the value of 1 if $i$ is a GCC country and $j$ is an European Union country.

DGCUS $_{\mathrm{ijt}}$ is a dummy variable, which takes the value of 1 if $i$ is a GCC country and $j$ is the United States.

$\mathrm{u}_{\mathrm{ijt}}$ is an error term.

$\beta_{0}, \beta_{1} \ldots \mathrm{B}_{14}$ are parameters to be estimated.

In the model above, $\beta_{1}$ and $\beta_{2}$ are expected to be positive as trade between two countries is posited to increase with their economic size (GDP). Larger countries trade more with each other than smaller countries as they have bigger potential for export supply and import demand ${ }^{5}$. Coefficients $\beta_{3}$ and $\beta_{4}$ are expected to be negative as larger countries tend to be more self sufficient or alternatively, for a given level of GDP, poorer countries (larger population) trade less than richer countries $^{6}$. However, as Zarzoso and Lehmann (2003) argue, the coefficients associated with the population of the respective countries may be positive or negative depending on whether the country exports less when it is big (absorption effect) or whether a big country exports more than a small country (economy of scale). The coefficient $\beta_{5}$ is expected to be negative, as greater distances between countries tend to increase transport and transactions costs. This coefficient is expected to decline in magnitude over time because of the development of more efficient transport and communication technologies ${ }^{7}$. The Border coefficient is

${ }^{5}$ Initially, the gravity model has been long criticized for its lack of a strong theoretical background. Later however many authors have shown that the model can be derived form the traditional and the new theories of international trade including Ricardian model, Hecksher-Ohlin Model and Increasing returns to scale models (see for example, Anderson (1979), Deaedorff(1995), Evenett and Keller(1998)).

${ }^{6}$ Sanso et al.( 1993) have shown that the model can be formulated alternatively by using the GDP and per capita GDP rather than populations as explanatory variables. Trade and GDP per capita are postulated to be positively related for a given GDP, or equivalently, richer countries (higher GDP per capita) tend to trade more with each other.

${ }^{7}$ The distance between countries is taken to be the distance between the two country capitals, which assumes that the capital of a country is its economic center. In some cases, however, economic distance and geographic distance are not the same (Bayoumi and Eichengreen,1995) 
expected to be positive assuming that a common border tends to facilitate trade.

The effects of GCC and other trade preference arrangements (PTA's) are captured by the coefficients $\beta_{7}, \beta_{8} \ldots, \beta_{14}$, which indicate the excess trade attributed to the PTA's, after controlling for the country size, distance, and other geographical factor. In particular, a positive and significant coefficient on the DGCC variable $\left(\beta_{7}\right)$ indicates that countries belonging to the GCC region trade more with each other than what would be predicted by their economic size and proximity factors, suggesting that the GCC, as a preference trade arrangement, leads to a gross trade creation ${ }^{8}$. The latter reflects the increase of the bloc intratrade regardless of whether it replaces domestic production or imports from nonmembers' countries (trade diversion). The inclusion of the dummy variable DGCCO captures whether or not the increase in the GCC intra-trade occurs at the expense of non-members countries (degree of openness). If the coefficient $\beta_{7}$ is positive and significant and $\beta_{10}$ is non significant, there is an indication that the GCC is associated with trade creation, whereas if $\beta_{7}$ is positive and significant and $\beta_{10}$ is negative and significant, there is an indication that the GCC is associated with trade diversion (Soloaga and Winters, 2001).

This approach of using dummy variables to model the trade creation and diversion effects of Regional Trade Arrangements has been widely used in the context of MERCOSUR, NAFTA, and African trading blocs ( Frankel et al. 1995; Subramanian and Tamirisa, 2003, Sologa and Winters, 2001; Azevedo, 2003)). For example, Sologa and Winters (2001) used this approach to investigate the effects of the "new wave" of regionalism, which includes regional blocs formed during the nineties. They concluded that there is no indication the new wave of regionalism boosted intra-bloc significantly and found a convincing evidence of trade diversion only for the $\mathrm{EU}^{9}$. Azevedo (2003) used a similar dummy variable modeling approach and pooled data to MERCOSUR and found that the bloc formation has not contributed to change intra-bloc trade beyond the non-discriminatory liberalization policy adopted by MERCOSUR countries. Jayasinghe and Sarker

\footnotetext{
${ }^{8} \mathrm{~A}$ positive coefficient $\beta_{7}$ indicates an increase in intra-trade whether this increase is the result of the reduction in intra-tariffs or comes about because trade has been diverted from the rest of the world.

${ }^{9}$ Soloaga and Winters approach differs from all others by using, instead of two, three sets of dummy for each trade bloc: one that captures intra-bloc trade, a second that captures the bloc effects on overall imports (imports from all countries, members and non members) and a third that captures the bloc effects on overall exports (export of bloc members to all countries). The latter, named by the authors as "export diversion" is a reflection of the welfare effects of the PTA on non- members' countries.
} 
(2004) applied the same approach to NAFTA for 6 commodities of the agri-food sector. Their findings showed that the share of intra-regional trade has grown within NAFTA but this growth was the result of trade displacement from the rest of the world.

\section{Estimation Issues}

Most empirical studies on Middle East international trade employed a single year or a pooled cross sectional regression method to estimate the gravity equation. The pooled cross sectional method (PCS) takes advantage of the large sample size to obtain more precise estimators and more powerful test-statistics. However, some authors argue that results obtained by the standard PCS suffers from a heterogeneity bias induced by missing variables that capture the individual effects of the trading -partner pairs (Baier and Bergstrand, 2005; Cheng and Wall, 2003, Zarzoso and Lehmann, 2003; Bayoumi and Eichengreen, 1995). In particular, Bayoum and Eichengreen (1995), argue that coefficients on dummy variables representing the regional trade agreements will pick up the effects of all timeconstant, non-controlled for factors (historical, cultural, geographical and other country-specific factors) that make the trading partners different in their trade performance.

The alternative is to use a panel data approach and estimate various versions of fixed effect models that account for the possible unobservable fixed, time invariant variables. One possibility is to specify the model as in Bayoum and Eichengreen (1995) in differences rather than levels of the dependent and independent variables to eliminate the fixed effects and obtain results which are not "contaminated" by the unobserved heterogeneity across countries. Using this method however eliminates also all the time-constant variables that are accounted for in the standard PCS model, including the distance and the border variables. Cheng and Wall (2003) estimated and compared various versions of a general fixed effect model and he concluded that the gravity estimates of the effect of integration are quite sensitive to the model specification..

In this paper the standard pooled cross-section (SPC) and the fixed effect model (FEM)in its differenced version are used and the results are compared (Table 3). Although some of the estimates are different across specification, both specifications lead to the same conclusion in terms of statistical significance and the effect of integration in the Middle East and North Africa region on trade flows. 
In particular, the effect of the GCC integration is trade creating in both specifications but its magnitude is much stronger in the fixed effect model. In the following, however, only the results of the SPC model will be discussed as their interpretation is more straightforward and estimates of the distance and the border coefficients are directly available.

\section{Results}

Table (3) presents the estimated parameters as well as their standard errors for the import gravity equation ${ }^{10}$. As in similar studies, the core variables of the gravity model have the expected signs and are all highly significant (at the $1 \%$ significance level), except the population of the trading partners. The coefficients of the GDP variables of the importers and exporters are positive, indicating that trade increases with the level of the GDP of both countries. However trade increases less than proportionately with the GDP of the importing country and more than proportionately with the GDP of the exporting country. The parameter estimate for the population variable is negative as hypothesized, indicating that larger, more populous countries tend to be more self- sufficient and therefore import less from other countries. Te distance variable is negative as expected, reflecting the increase in trade cost as the distance between the two trading partners increase. The sign of the border variable indicates that countries which share a border trade more with each other than countries that do not share a border.

The trade potential of the of the various regional trade arrangements is indicated by the sign and the magnitude of the dummy variables' coefficients. The intra-bloc trade coefficient (DGCC) for the GCC countries is positive and highly significant (at $1 \%$ level) indicating that, after controlling for the GDP, population and proximity factors, the GCC trade arrangement actually promoted trade integration among members' countries. The magnitude of this coefficient shows that the GCC members traded two times more with each other $\left\{\mathrm{e}^{1.19}-1\right\}$ than would be predicted by the basic gravity model. These results agree with those reported by Bolbol and Fatheldin (2005) and Soloaga and Winters (1998) despite differences in the country coverage and the data sample size. The results also indicate that the intensive GCC

\footnotetext{
${ }^{10}$ As argued by Al-Atrash and Youssef, only the import equation is likely to provide insights on the Middle East trade given the bias resulting from oil exports. Export data as published by COMTRADE, are not quite reliable as they do not account for re-exports, which constitute a large proportion of total exports of middle East countries, particularly GCC countries.
} 
Table 3.Gravity model regression results for the import equation

\begin{tabular}{|c|c|c|c|c|}
\hline & \multicolumn{2}{|c|}{ Pooled Cross-Section (PCS) } & \multicolumn{2}{|c|}{ Fixed Effect Model (FEM) } \\
\hline Variable & Estimated Coefficients & $\mid$ t-statistics $\mid$ & Estimated Coefficients & $\mid$ t-statistics $\mid$ \\
\hline$\overline{\mathrm{C}}$ & $15.782^{*}$ & 66.801 & $-0.103 *$ & 3.044 \\
\hline $\mathrm{GDP}_{\mathrm{i}}$ & $0.696^{*}$ & 17.157 & $0.503^{*}$ & 2.710 \\
\hline $\mathrm{GDP}_{\mathrm{j}}$ & $1.194 *$ & 88.452 & $1.150 *$ & 89.149 \\
\hline $\mathrm{POP}_{\mathrm{i}}$ & 0.034 & 0.903 & $0.380 *$ & 2.896 \\
\hline $\mathrm{POP}_{\mathrm{j}}$ & $-0.151 *$ & 10.346 & $-0.211 *$ & 14.922 \\
\hline DIST $_{i j}$ & $-0.782 *$ & 28.179 & & \\
\hline BORDER $_{i j}$ & $0.335^{*}$ & 2.863 & & \\
\hline DGCC & $1.199 *$ & 6.289 & $2.557 *$ & 10.697 \\
\hline DGCCO & $0.298^{*}$ & 3.354 & $0.227 *$ & 3.611 \\
\hline DMASR & $0.835^{*}$ & 4.892 & $2.665^{*}$ & 11.470 \\
\hline DMAGR & $0.736^{*}$ & 4.755 & $1.317 *$ & 6.647 \\
\hline DGCCMAS & $1.426^{*}$ & 7.490 & $1.608^{*}$ & 5.759 \\
\hline DGCCMAG & $-2.378 *$ & 12.364 & $-3.992 *$ & 13.834 \\
\hline DGCCUSA & $-0.615^{*}$ & 2.715 & -0.0930 & 0.277 \\
\hline DGCCEU & $-0.367 *$ & 4.691 & $-0.477^{*}$ & 4.291 \\
\hline GCCPR2 & -0.250 & 1.064 & -0.256 & 0.737 \\
\hline GCCPR3 & -0.452 & 1.919 & -0.155 & 0.447 \\
\hline GCMASPR2 & -0.205 & 0.770 & -0.222 & 0.578 \\
\hline GCMASPR3 & $-1.378 *$ & 5.376 & $-1.341 *$ & 3.539 \\
\hline GCMAGPR2 & 0.229 & 0.870 & 0.676 & 1.736 \\
\hline GCMAGPR3 & -0.130 & 0.498 & -0.248 & 0.639 \\
\hline $\mathrm{R}^{2}$ & 0.64 & & 0.596 & \\
\hline $\mathrm{N}$ & 8045 & & 8044 & \\
\hline Log likelihood & -15153.7 & & -16044.2 & \\
\hline
\end{tabular}

*significant at $1 \%$ or $5 \%$

intra-trade occurred without trade diversion from the rest of the world as shown by the positive and significant estimated parameter for the "degree of openness" variable (DGCCO). The magnitude of this coefficient indicates that the GCC countries traded with the rest of the world (non member countries) $39 \%$ more than what would be expected. Thus, during the period of analysis, the GCC countries increased their trade integration with themselves as well as with the rest of the world suggesting that the GCC -as a preference trade arrangement- was a trade creating rather than trade diverting arrangement.

The GCC trade with other Arab countries is captured by the dummy variables (DGCCMAS) and (DGCCMAG). The results show that the GCC-Mashreq trade is more than expected while that of the GCC-Maghreb is less than expected. Therefore a 
trade arrangement designed to reduce trade barriers between GCC and the MU would enhance their trade, given the already active GCC-Mashreq trade.

Trade between GCC and both the European Union and the Unites States is less than expected as indicated by the negative and highly significant coefficients associated with the GCCEU and GCCUSA variables. This suggests that there is a room for trade intensification between the GCC and the EU as well as with USA, and the newly signed Free trade areas agreements have the potential of achieving greater integration with both partners.

To check whether there has been improvement over the years of the GCC intratrade and the GCC trade with its main partners, particularly those in the Arab region, the data set was divided in three periods, of 4 years each: period 1:19931996, period 2:1997-2000, and period 3: 2001-2004. A new variable, which is the product of the dummy time-periods and the dummy trade blocs, is constructed to capture the interaction effect of the time period with the trade bloc dummy on bilateral trade. The interaction variables included are: GCCPR2, GCCPR3, GCMASPR2, GCMASPR3, GCMAGPR2, and GCMAGPR3, GCCOPR2, GCCOPR3, which represent respectively GCC intra-trade, GCC trade with the Mashreq, GCC trade with the Maghreb, and GCC trade with the rest of the world, in period 2 and in period 3 (period 1 is omitted as it represents the base period).

Results (Table 3) show the coefficients of the GCC intra-trade for period 2 and period 3 are both negative but none of them is significant. This indicate that there is no noticeable change in the GCC intra-trade in the 19967-2000 and 2001-2004 periods compared to the base period 1993-1996. That is the potential of trade among the GCC countries has been exhausted during the early years of the establishment of the GCC trade arrangement. The intensity of the GCC trade with the Mashreq has declined over the 2 periods and significantly so during the 20012004. With the Maghreb, the coefficient for the 1997-2000 period is positive and turns out negative in 2001-2004 periods but none of them is significant. So, considering that the year 1997 represents the beginning of the implementation of the Greater Arab Free Trade (GAFTA), the results indicate that the effect of GAFTA is at minimum marginal on intensifying trade between GCC and its Arab partners.

\section{Conclusion}

This study has investigated the potential of trade of the GCC countries within 
the context of old and emerging preference trade arrangements in the MENA region. Contrary to the stylized view that MENA countries trade little with each other, the findings of the study indicate that GCC countries actually trade more with each other than expected on the basis of the underlying trade determinants. In quantitative terms, the GCC countries are found to trade two times more with each than would be predicted by the basic gravity model. Further analyses indicate that the GCC as a preference trade arrangement has actually "created trade" and that trade creation has occurred without much "trade diversion". This is probably the result of the relative trade openness of the GCC toward the rest of the world compared to all other trade arrangements in the MENA region.

The GCC intra-trade did not seem however to change significantly over the years and had probably reached its full potential during the 93-96 period. The newly created GCC Custom Union is therefore promising in enhancing new opportunities of trade as it goes beyond the removal of tariffs to the elimination of non tariff barriers and the establishment of common standards and regulatory regimes.

On the other hand, the results related to the GCC trade intensity with other trade groups are not clear-cut. GCC Trade with the Mashreq countries are more than expected, while it is less than expected with the Maghreb countries despite the implementation of the GAFTA a decade ago. Therefore, the deepening of the GAFTA to involve a much wider product and service coverage may prove to be successful in reducing transaction costs and enhancing trade with the Maghreb bloc. The GCC trade with the European Union and the US is found to be quite intensive despite the non existence of a formal trade arrangement between the GCC and both blocs during the time period used in this analysis. The recent signature of free trade areas agreement between GCC countries and the United Sates will probably facilitate some trade in goods through the elimination of nontariff barriers, but more significantly it will enhance trade in services trough direct foreign investment and the deepening of capital markets.

Received 13 June 2007, Accepted 17 October 2007

\section{References}

Al-Atrash, H., and T. Youssef. 2000. Intra-Arab trade: is it too little?. IMF Working Paper WP/00/10. International Monetary Fund, Washington, DC. 
Anderson, J.1979. Theoretical foundation for the gravity equation. American Economic Review 69 (1):106-116.

Azevedo, A. What has been the real effect of Mercosur on trade? A gravity model approach. http://www.ufrgs.br/ppge/pcientifica/2002_01.pdf .

Baier, S., and J. Bergstrand. 2005. Does free trade agreements actually increase members' international trade. Working paper 2005-3. The Federal Reserve Bank of Atlanta.

Bayoumi, T., and B. Eichengreen.1995. Is regionalism simply a diversion? Evidence from the evolution of the EC and EFTA. NBER Working paper No 2978.

Bolbol, A. and A. Fatheldin. 2005. Intra-Arab exports and Direct Investment: An empirical analysis. Economic Policy Institute. Arab Monetary Fund, Abu Dhabi.

Deaerdorff, A.1995. Determinants of bilateral trade: Does gravity work in a neoclassical world? NBER working paper \# 5377, Cambridge, MA.

Evenett, S., and W. Keller.1998. On the theories explaining the success of the gravity equation . NBER working paper \# 6529, Cambridge MA.

Frankel, J., S. Stein, and S. Wei, 1995. Trading blocs and the Americas: the natural, the unnatural, and the supernatural. Journal of Development Economics, 47:61-95.

Havrylyshyn, O. and P. Kusnel. 1997. Intra-industry trade for Arab countries: an indicator of potential competitiveness. IMF Working Paper, WP/97/47/.

Jayasinghe, S. and R. Sarker. 2004. Effects of regional trade agreements on trade in agrifood products: evidence from gravity model using disaggregated data. Working paper 04 WP 374. C ARD, Iowa State University, Ames, Iowa.

Kamil. H and A.Ons. 2001. The pattern of bilateral trade under a regional trade arrangement; an application to MERCOSUR's trade flows. Paper presented at LACEA Annual Meeting, Montevideo, Uruguay.

Nugent, J. 2002. Why does MENA trade so little? Background paper to the MENA development report 2003. The World Bank. Washington D.C

Sanso, M., R. Cuarian and F. Sanz. 1993. Bilateral trade follows, the gravity equation, and functional form. Review of Economics and Statistics 75: 266-275.

Subramanain A., and N. Tamirisa. 2003. Is Africa integrated in the global economy. IMF Staff Paper, 50 (3):352-372.

Soloaga, I. and L. Winters, 2001. Regionalism in the nineties: What effect on trade? North American Journal of Economics and Finance12:1-29.

WTO. Regional trade arrangements. http://www.wto.org

Zarzoso, I and F. Lehmann (2003).Augmented gravity model: an empirical application to MERCOSUR- European Union trade flows. Journal of Applied Economics 6(2):291316. 


\section{Appendix:}

List of countries used in the analysis

Reporters: MENA (19 countries)
Saudi
Bahrain
Oman
UAE
Kuwait
Qatar
Algeria
Tunisia
Morocco
Egypt
Syria
Jordan
Lebanon
Turkey
Iran
Mauritania
Libya
Iraq
Yemen

Partners (60 countries)

MENA( 19 countries)

EU (15)

Asia (12)

Africa(7)

S. America (3)

USA

Canada

Australia

New Zeeland 